\title{
História
}

\section{Una educación para todos y de calidad, una máxima ética y política ${ }^{1}$}

\section{Quality Education for all, ethical and political principle}

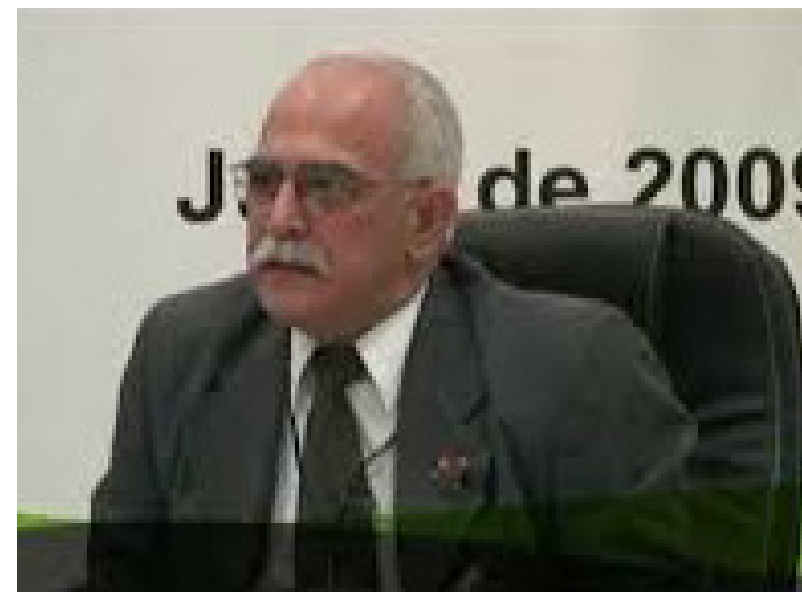

Guillermo Arias Beatón - Facultad de Psicología, Universidad de La Habana

Estimados delegados al Congreso de ABRAPEE, es un gran honor para mí realizar esta conferencia con un tema tan importante. Un hijo de este pueblo, Frei Beto, dijo una vez que el problema de este mundo era esencialmente y sobre todo, un problema ético. Sobre eso hemos de hablar y trabajar.

Lo primero que deseo decir porque lo considero ético, es reconocer cómo he vivido las experiencias que he tenido en mi participación en algunas de las tareas de ABRAPEE, los sentidos y significados que han tenido para mí.

Pienso que ustedes son una organización que lucha, en las condiciones que le permite la sociedad, por mejorar la labor educacional en Brasil. Luchan a contra corriente, no se pliegan a lo establecido y lo hacen de acuerdo con la concepción que poseen sobre el desarrollo del ser humano, que está produciéndose, constantemente y de manera crítica. Esto es ya un hacer profundamente ético y político.

Resulta encomiable, la labor que ustedes realizan contra la medicalización, porque es un enfrentamiento al

\footnotetext{
1 Conferência apresentada no XI Congresso Nacional de Psicologia Escolar e Educacional, ocorrido em agosto de 2013, em Uberlândia, MG.
}

mercantilismo sin límites y a lo inhumano de las sociedades modernas y postmodernas, que lejos de resolver los problema, crean otros mas graves e insolubles aunque, el placebo de hacer más tranquilos y manejables a los niños parece justificarlo, cuando realmente aumenta la alienación.

Lo peor de este hecho, es que no se enfrentan y atienden los verdaderos males que producen que los escolares no aprendan cómo pudieran y por ello se siguen incrementando las poblaciones de escolares con problemas en el aprendizaje y el desarrollo, debido a las deficiencias de la sociedad, a las desigualdades sociales y a las insuficiencias de los sistemas educacionales, entre otras condiciones sociales y culturales desfavorables que producen las sociedades actuales.

Lo que escuché, en el evento de Sao Paulo, sobre las concepciones y las prácticas acerca del diagnóstico, la intervención y la labor del psicólogo en las escuelas, me hizo muy feliz y uno más entre ustedes, porque son también labores muy importantes, incluso si algún día se mejoraran los programas educacionales. Son de un hacer profundamente ético y una magnifica política, el colocar al ser humano en el centro de atención. 
Las posiciones que se oponen a un diagnóstico clasificatorio, estigmatizante, inmanente al sujeto y que lo culpa solo a él de sus desgracias, son una muestra de este quehacer, tal y como lo denunció hace ya más de 30 años Maria Helena Souza Patto. Las discusiones iniciadas por esta autora han tenido continuidad en la labor de otros psicólogos y teóricos que siguen trabajando por la identidad de la psicología escolar y educacional, asumiendo una perspectiva crítica y ética de la misma. Es una lucha contra lo que nos llega de las concepciones y las prácticas incorrectas de la psicología y la pedagogía tradicional (Patto, 1993). Esto aunque es una labor específica, referida al hacer, es también profundamente teórica y metodológica. En eso deseo insistir, porque es muy difícil mejorar o transformar una práctica si no se asume una concepción o explicación teórica y metodológica integral y plena sobre el problema en cuestión (Arias, 2001, 2005, 2006). Esto forma parte inseparable del método con el que trabajamos. (Arias, 2005; Tanamachi, 2007; Netto, 2011).

El método que me guía en este análisis crítico, para hacer las propuestas que formulo, se basa en las necesidades y posibilidades de transformar la realidad, y no solo contemplarla (Marx, 1986; Lenin, 1961; Vygotski, 1991, 1993, 1994, 1996). Es imprescindible en este proceso de transformación poseer un dominio del problema que nos ocupa, un cierto grado de conocimientos de su génesis, para lo que se requiere de un estudio y análisis crítico de lo que existe, que nos permita elaborar o reelaborar otras explicaciones, sobre bases teóricas y metodológicas, a partir de los hechos concretos de la vida real que afectan a los seres humano inmersos en los problemas y sus historias, así como, los datos que se vayan obteniendo en las propias prácticas transformadoras.

Lo que se hace con la concepción de la "queja escolar", es una puesta en práctica de lo mencionado y una respuesta critica, ética y política desde esta organización a los problemas que produce un sistema educacional deficiente (Souza \& Belluzzo, 2010). Con el nombre de "queja escolar" se enfatiza, muy acertadamente que las víctimas del sistema educacional, representan una queja, una protesta, para el sistema escolar. Esto habría que divulgarlo más, explicarlo, hacerlo más evidente, mostrar lo que se puede lograr en el trabajo con estos escolares y hacer al pueblo mas consciente para que pueda tener una incorporación y participación más activa en los logros de los objetivos que ustedes como organización se han trazado, transformar la realidad y la lucha por la identidad de la Psicología Escolar y Educacional y las contribuciones que esta puede ofrecer para a sociedad y el ser humano.

Estoy convencido que para producir una transformación de la educación actual es necesario que la población, O sea el pueblo, demande una educación para todos y de calidad, que permita la formación integral de la personalidad. Es la calidad que demandan las personas del pueblo la que se necesita.

Fue para mí sumamente estimulante lo que me pidieron que abordara en el Evento de Maringá, sobre si las causas de las dificultades de aprendizaje son producto de la inteligencia o de las deficiencias de los sistemas educacionales. Este dilema también está presente en las deficiencias de un sistema educacional, que aunque declara la necesidad de una atención individual, en realidad no las considera y por ello, solo poseen más probabilidad de tener éxito, los estudiantes con mejores condiciones de vida material, social y educacional, que les brinda la sociedad desigual e injusta. Habría que divulgar y mostrar lo que se puede lograr con programas transformadores de este estado de cosas.

Estas y muchas otras experiencias con ABRAPEE, me permiten decir que no tengo que persuadir de estos problemas y sus soluciones a los miembros y directivos de esta organización consciente de lo que está ocurriendo y de su papel. Solo insisto e insistiré, porque me lo han solicitado, en algunos aspectos que de acuerdo con mi experiencia sería importante tomar en cuenta en esta labor, sobre los que posiblemente ustedes ya han pensado, para contribuir a hacer conciencia de lo que hay que hacer en la sociedad y en la educación para disminuir o evitar, los problemas que se presentan.

No creo que las soluciones a los serios problemas que viven la educación y el desarrollo personal en el mundo, sean fáciles de resolver, incluso aunque mañana, por medio de un milagro o un sueño, se produzca una transformación radical del sistema social, del tipo de relaciones sociales y de producción que impera.

Incluso los procesos revolucionarios que existen o han existido, a pesar de los avances, todavía trabajan por mejorar la educación, porque esta labor resulta compleja y necesita del movimiento de un tiempo prolongado para eliminar los males acumulados durante milenios. Sin embargo, y siendo consecuente con el marxismo, hay que trabajar en la superestructura, mostrando todo lo que se pueda hacer para lograr mejores resultados, estén o no resueltos los problemas estructurales. Esta puede ser una de las tareas que conscientemente se trace ABRAPEE.

Otro ejemplo de luchas contra estos problemas son las protestas de los estudiantes por una educación pública de calidad en pleno tercer milenio. Les correspondería hacer algo también a los trabajadores, a los profesionales, a los intelectuales, a las ciencias y a los científicos más identificados con los que sufren y a las organizaciones e instituciones mas conscientes para mejorar las condiciones de la educación del gran número de niños y niñas que no asisten a las escuelas, de los niños y niñas hambrientas y que padecen de desnutrición, de los estudiantes que no aprenden como deberían y fracasan en los estudios. ¿No se podría trabajar por mostrar que los niños y niñas más desfavorecidos cuando se les enseña y se les atienden de acuerdo con sus características y condiciones, logran mitigar o eliminar sus problemas de adaptación escolar y las dificultades para aprender? ¿Qué escolar no añora estudiar en una buena escuela, ser amado y apoyado en sus desgracias? En mi trabajo con estos niños y niñas desfavorecidos, con una enorme queja o protesta escolar, no me ha sido difícil encontrar escolares, que desean mejorar y aprender; incluso en nuestros cursos aquí en Brasil, hemos llegado a estudiar a jóvenes de 20 o 
más años que solo sueñan con encontrar a alguien que los haga aprender como aprendieron sus coetáneos.

Este hecho tiene su historia, comenzó desde los faraones, cuando las clases dominantes decidieron imponer la condición de que solo las élites eran las educables y los otros, pueblos y esclavos serían los entrenados o preparados, para realizar las tareas productivas que mantuvieran a los privilegiados (Manacorda, 2010; Ponce, 1975). Esto solo ha cambiado en la forma, más no en su esencia. Hoy en día, estas prácticas, son solo más sutiles, más indirectas e imperceptibles, menos comprometedoras desde el punto de vista ético y político. Se logra hacer sentir culpable a las personas, a las familias y no al sistema productivo y de distribución de las riquezas en la sociedad, que son en definitiva los que producen y mantienen las ineficiencias de los sistemas educacionales que no se ocupan, ni atienden, como lo necesitarían los grupos sociales mas desfavorecidos (Portes, 2005, 2006, 1999; Calejon, 2011). Las personas llegan a creer, tanto las que hacen estas políticas como las que la sufren que las causas están en el propio ser humano que no es capaz porque su mente o su psicología no le permiten desarrollar convenientemente los procesos cognitivos, porque su DNA daña todo su funcionamiento o porque su padre o su madre no los educaron bien o no se ocuparon adecuadamente, porque viven en lugares desfavorecidos, porque hay disfunción familiar, porque son mas o menos inteligentes, entre otras razones. Con todo esto se logra una explicación causal muy eficiente, aunque incompleta, no integral y alienada.

En la sociedad moderna y posmoderna, se llega a defender, incluso que es un derecho de los niños o niñas el no aprender y que intentarlo es un acto de violencia. Les comento a las ciencias y a los científicos ¿No habremos nosotros contribuido en algo a estos males que todos, todos sin excepción vivimos?

Cuán importante sería tomar conciencia del sentido y el significado que creo tiene aquel comentario de que los hijos que viven en medios enriquecedores, de familias letradas y con bibliotecas, aprenden mejor a leer y escribir que los restantes. ¿por qué a partir de este dato no se crea una educación infantil necesaria $Y$ desarrolladora para todos y en especial para aquellos que viven en condiciones desfavorables? ¿Produce o no produce una educación rica en contenidos culturales un buen desarrollo? ¿Para quienes se deja el buen aprendizaje y desarrollo, para los que tienen una influencia educativa en familias letradas y con bibliotecas o para los que no las tienen? ¿No será esta una forma sutil, indirecta e inconsciente de aplicar una especie de "selección natural" que no es ni biológica, ni humana, ni ética; porque el desarrollo es, en realidad, de naturaleza social y cultural y por lo tanto, al no facilitarles a todos un tipo de educación promotora del desarrollo, producimos fracaso escolar, segregación, discriminación y estigmatización en escolares desfavorecidos?

Solo me gustaría mencionar, en este momento, una de las dudas que Charles Darwin reflejó en su libro sobre su viaje en el Beagle, y que guarda mucha relación con estas preguntas. Dijo Darwin:

\section{Si la miseria de nuestros pobres no es causada por las leyes de la naturaleza, sino por nuestras instituciones, cuan grande es nuestro pecado. (Gould, 1997 p.6 ).}

Creo que esta organización (ABRAPEE) y sus miembros pueden incrementar el trabajo en la educación de la conciencia popular, contra las interpretaciones alienantes de estos datos científicos, que solo perjudican a una parte de la población, a los mas desfavorecidos.

Hay un ejemplo que resulta esencial, para este tipo de educación, que me place comentar, ¿cómo es posible que escolares con lesiones residuales y alteraciones funcionales no puedan aprender y desarrollarse plenamente, si las personas sordas y ciegas, que tampoco pueden lograr un lenguaje verbal, cuando reciben una educación desde la más temprana edad, acorde y ajustada a sus características biológicas y personales, aprenden y se desarrollan de manera análoga a las del resto de sus coetáneos? ¿Habrá que respetar también a estas personas dejando que no aprendan porque no poseen un buen funcionamiento de los analizadores auditivos y visuales? ¿Tendremos que regresar definitivamente a la idea de Aristóteles de que las personas con estos déficits no pueden aprender y por lo tanto no se les debe enseñar? ¿Será esto ético y humano?

Esta educación popular ha de extenderse, también para contrarrestar la propaganda y la divulgación que en la actualidad continua promoviendo una explicación biologicista sobre nuestro desarrollo. Que incluso no se corresponde con los últimos datos de las ciencias biológicas (Gould, 2007; Lewontin, Rose y Kamin, 1987; Kamin, 1983; Arias, 2001, 2005a, 2006; Nature, 2001; Venter, 2001; Moysés \& Collares, 2010).

Lo habitual es brindar con datos científicos parciales y fuera de contexto, una justificación a los males sociales y culturales, creados por la sociedad. El propósito, implícito, a lo mejor inconsciente, es crear un fetiche. Esas ideas, invitan a desviar los análisis de las verdaderas causas de los problemas en las escuelas, la educación y la sociedad y la ubican en lo biológico, lo social personal y lo genético. Entonces se insiste, como paliativo y al margen de la escuela, en entrenar y ejercitar los procesos aislados con el empleo de programas computacionales sofisticados, que recuerdan a los procesos más simplistas, mecánicos y estériles de la formación de lo humano.

Acaso podemos sostener que en un mundo con tantas posibilidades culturales, se continúen utilizando de manera tan mecanicista, los medios y procedimientos que, empleados de otra forma, pudieran desarrollar sujetos más críticos, más creativos y reflexivos, con un pensamiento teórico que les permita no solo contemplar la realidad, sino además luchar o trabajar por transformarla. Qué lástima que las investigaciones sobre estos aspectos se realicen sin insistir con claridad que la buena educación y la buena en- 
señanza son las que producen que el sujeto aprenda y como resultado de este, se obtenga un buen desarrollo. Incluso sabemos por estudios de las neurociencias en los años 70 del siglo pasado, que mediante una rica y estimulante educación, se garantiza una mejor formación y desarrollo de las estructuras y las funciones cerebrales, creándose las condiciones para un buen desarrollo y una compensación de los procesos alterados (Greenough, 1975; Chang \& Greenough, 1985; Griffiths, Gelbait, Miller \& Lewontin, 1999; Arias, 2006; Mustard, 2006).

Además, por medio de esta misma educación de calidad, se garantiza la formación de una subjetividad multilateral e integral, una conciencia, un pensamiento teórico y práctico capaz de realizar las mas profundas criticas y transformaciones de la realidad. Lograr la formación y desarrollo de las necesidades, intereses, emociones, motivaciones, conocimientos y habilidades básicas, que permitan la constitución de un sujeto, que posee un cerebro, bien formado y desarrollado por la acción de lo social, de lo cultural y lo propiamente psicológico que se va conformando, con mejores aprendizajes y mas integrales contenidos en su educación.

Para lograr definitivamente esto que estamos diciendo, las ciencias pedagógicas, psicológicas y neurológicas ya cuentan con información suficiente, solo habría que trabajar, teniendo en cuenta lo dicho por otros pensadores y científicos desde los siglos XVI, XVII y XVIII hasta nuestros días, para eliminar el analfabetismo que existe en la sociedad, crear programas de educación popular que estimulen a las personas a elevar sus niveles de escolaridad y su cultura. Garantizar una educación infantil para todos y de calidad, que compense los problemas con los que llegan los escolares a las escuelas.

Una población con mayor nivel de escolaridad tiene mucha mas posibilidades de alcanzar, dominar y disfrutar con mayor amplitud y profundidad los logros de la cultura y aplicarlos en su beneficio. Pueden garantizarles una mayor educación a sus hijos e hijas e incluso cuidarlos mejor. Este tipo de educación contribuye a que el sujeto sea crítico con la información y la propaganda que recibe, que distorsionan las explicaciones de sus problemas y males. Si esto se lograra, además de ayudar a producir felicidad, independencia, autonomía y autorrealización en las personas, se podría obtener mayor tranquilidad social, que contribuiría a una disminución de la violencia y las actividades delictivas.

Pero, parece ser que no es esto lo que se desea en las sociedades actuales, sino conocer los posibles secretos del cerebro, porque con ello se piensa que se podrá dominar, guiar o producir un comportamiento humano robotizado, homogéneo, estandarizado y de acuerdo con los intereses dominantes, producir fuerza de trabajo más eficiente, obediente y acrítica. No por gusto los estudios del genoma humano y los del cerebro fueron y están siendo financiados por las grandes empresas y grupos trasnacionales de la medicina y la industria armamentista, que solo desean controlar y dominar el Mundo. Esto es algo que hay que saber para poder adoptar ante cada hecho una postura ética y política consecuente y para orientar nuestra labor educativa y auto educativa.

Las ciencias, los científicos y los profesionales para obrar éticamente y para favorecer las buenas políticas necesitan conocer estas cosas al igual que el pueblo que las sufre y padece. Por eso insisto en que educar y contrarrestar las manipulaciones pseudocientíficas que se hacen, es una labor que hay que incrementar en esta grande y honrosa organización, promotora de este encuentro, que lucha desde una posición ética por la producción de políticas más consecuentes con lo humano.

Creo en las ciencias no obstante, el sometimiento que sufren por el lucro y el mercantilismo de las sociedades actuales, ellas no podrán ser definitivamente manipuladas por las concepciones ideológicas predominantes, porque también confió en los científicos, en su seriedad, rigor y ética. Por eso si los estudios y las investigaciones son serias y rigurosas van a concluir lo contrario de lo que se pretende por la lógica mercantilista.

Pasará como ya pasó con las conclusiones de los científicos acerca del estudio del genoma humano, pero que no se han divulgado como exige un hacer ético. En estas investigaciones, por ejemplo, se partió de la hipótesis biologicista de que todo lo humano e incluso la personalidad era explicada por medio de las funciones del DNA y de la herencia biológica, y que esto lo debía de garantizar un poco más de 75 mil genes. En las publicaciones del 2001, en las revistas Nature y Science, se informó que el número de genes encontrados en el genoma humano era mucho menor, solo entre 30 y 35 mil genes lo que llevó a decir que parecía que el ambiente tenía una mayor influencia que lo que se pensaba (Nature, 2001; Venter, 2001; Arias, 2005, 2006). Incluso siguiendo con esta explicación, que no nos brindan los medios de información, otros trabajos científicos, han llegado a destacar que el mal llamado DNA chatarra, el que no codifica para una característica específica, y que representa casi el 90\% del genoma, está relacionado con las funciones reguladoras o mediadoras entre el genoma y los diferentes componentes del medio que entre otros, actúan sobre el sujeto, incluyendo el social y el cultural. ¿Qué significa esto? ¿Por qué no se divulga a la gran población con la amplitud que se merecen estos resultados de los estudios del genoma humano?

Porque ello puede contribuir a explicar que las desventajas y males de la población infantil no son, un producto lineal de su herencia biológica o de un funcionamiento biológico deficiente. El pueblo no es dueño de este saber, de que el ambiente y sobre todo el social, el cultural y el educativo como expresión de aquellos, poseen un papel mucho mas importante en el desarrollo y la formación de los humanos, de lo que se piensa y divulga. Que el genoma y la biología tienen un sistema de funcionamiento lo suficientemente flexible y diverso que le permite actuar en estrecha interdependencia con los contenidos y las funciones del ambiente, incluido el social y el cultural. Y si estos son de calidad, el desarrollo y el aprendizaje serán de calidad e incluso con 
posibilidades de corregir y compensar los efectos de los déficits biológicos.

Estos datos fundamenta con creces la lucha contra la medicalización (Moysés y Collares, 2010; Souza, 2010) y lo de la "queja escolar". Y demuestra que hay suficientes datos y evidencias en el mundo y aquí en Brasil, mostrados en su oportunidad por destacadas científicas y profesionales miembros de ABRAPEE, para intensificar la educación a todos sobre estos asuntos. Pero además, existen conocimientos desde los primeras décadas del siglo pasado en la psicología y recientemente ratificados por las neurociencias, de que los efectos que se producen como consecuencias de los déficit biológicos o de las condiciones sociales y culturales desfavorables, pueden ser compensados y corregidos cuando se logra la educación con la calidad necesaria y se atienden los problemas sociales y materiales de las personas.

En relación con las investigaciones del cerebro, esperamos que en algún momento, se produzca lo mismo, corroborándose la hipótesis que formuló Vygotski en los tempranos años de 1930 cuando dijo que también lo biológico en el ser humano tiene una naturaleza cultural (Vygotski, 1987, 1991; Greenough, 1975; Chang \& Greenough, 1985; Arias, 2005, 2006).

En la actualidad los datos de las investigaciones de las neurociencias confirman lo que ya, fue planteado por científicos de la pedagogía y la psicología, como Vives, Ponce de León, Huey y Comenio en los siglos XVI, XVII y XVIII que todos los seres humanos debían de ser educados porque tenían posibilidades de ello (Vives, 1997; Comenio, 1983; Vygotski, 1989; Arias, 2005), por supuesto que pensaban en el cerebro, como parte de este proceso, pero sobre todo se referían a lo humano, al pensar y al hacer creador, a la educación que era para ellos y para mí, lo esencial que permite el buen desarrollo de las funciones del cerebro haciendo al ser humano, una personalidad plena e integral, que no se reduce ni al cerebro ni a su funcionamiento (Galperin, 1988; Golder, 1986).

Los neurocientíficos de hoy corroboran, una vez más, que el juego infantil es muy importante para el desarrollo del cerebro, yo insisto, para la formación y desarrollo integral del ser humano, al igual que dijeron Froebel, Vygotski, Elkonin y muchos pedagogos y psicólogos más, desde el siglo XIX. El juego no es un simple entretenimiento, sino también y sobre todo un poderosísimo medio para lograr el desarrollo intelectual, emocional, volitivo por medio de la formación y desarrollo de la función simbólica en el niño que cambia cualitativamente el desarrollo humano (Vygotski, 1991; Elkonin, 1984).

Existen formas diseñadas en la pedagogía y en la psicología, para que el trabajo en las escuelas promueva el desarrollo infantil, por medio de la formación de la función simbólica, del signo y los significados (Vygotski \& Luria, 2007). Este es el valor de lo que nos brindan y corroboran los mas recientes logros de las neurociencias. Creo que presentarlo de esta manera es lo verdaderamente ético porque ayuda a tener una mejor comprensión histórica de cómo se han producido los conocimientos sobre el desarrollo y la formación humana, pero que, hasta hoy, no se emplean convenientemente en beneficio del ser humano.

Por eso los sistemas educacionales y las escuelas han de trabajar con calidad para lograr, un sistema integral, un desarrollo multilateral mediado por lo biológico, lo social, lo cultural y lo psicológico, para lograr el desarrollo pleno y multilateral de la personalidad en los seres humanos.

Las ciencias, desde lo ético y la política humanista, deberían existir para el beneficio de la naturaleza y de los seres humanos y no para otros fines. El contradictorio Francis Bacon nos dejó una de las ideas más sensatas de su obra, que las sociedades hasta ahora no han tomado en consideración. Bacon llegó a decir que a la naturaleza solo se le domina obedeciendo sus leyes y que esa era la razón por la que había que llegar a conocer sus secretos (Bacon, 1961).

Si nos damos cuenta y comprendemos el mensaje, en última instancia ésta es la razón de ser más importante de la ética del científico y de las ciencias, como parte de la sociedad y de la cultura humana. Sin embargo, hasta ahora esto se ha violado, por ideologizar los datos de las ciencias, por acomodarlos a los intereses de las grandes empresas, a la mercantilización, a las políticas existentes e impuestas por las máximas de que el fin justifica los medios o vale todo, que son para mí, análogas (Hinkelammert, 2006).

Por no tener en cuenta esta gran verdad es que estamos, no solo destruyendo la naturaleza, sino, desaprovechando las inmensas posibilidades del ser humano, al no recibir la educación de calidad y ajustada a sus características, dados los conocimientos, que ya existen sobre el desarrollo y la formación del ser humano y las condiciones que lo producen.

Las ciencias no son solo o esencialmente para publicar, lucrar, hacernos académicos, máster, doctores, poseer un estatus, promover la crítica sin transformación, como nos trata de obligar a vivir la sociedad actual, son ante todo para que, empleando los conocimientos que existen, podamos dilucidar por medio de la crítica comprometida, qué es lo más conveniente HACER para mejorar la educación y con ello la naturaleza humana. Esto sería lo profundamente ético y lo políticamente aceptable, y por lo que esta organización trabaja y seguirá perfeccionando su quehacer, insistiendo en la ampliación y profundización de una labor para promover o que se hagan nuevas políticas y prácticas educacionales, que transformen el estado actual de la educación.

En este sentido y propósito, se enmarca el papel que pienso tienen las ciencias y sobre todo los científicos en el proceso educativo y del desarrollo del ser humano. Dentro de ellas la Psicología y la Pedagogía y en particular la Psicología Educativa y Escolar tiene que atender los campos interconectados entre aquellas dos esenciales ciencias para contribuir a la educación, el aprendizaje y el desarrollo de los estudiantes. Estas ciencias son las encargadas de escudriñar las explicaciones, que aun no son del consenso, acerca de la naturaleza, el origen y el cómo nos hacemos consciente y autoconscientes de nuestra existencia, nues- 
tras vidas y de la labor que hacemos en ella. La psicología, la pedagogía y en particular la psicología educativa y escolar son las ciencias que deben mirar hacia la vida real que viven los seres humanos en relación con el mundo interior que se forma a partir de ella, para explicar su esencia, de dónde viene, cuál es su fuente u origen y cómo se producen las capacidades y posibilidades no solo de entender las cosas, sino de modificarlas en virtud de una mejor y activa adaptación del ser humano.

Uno de los problemas más acuciantes que ha de resolver la psicología como ciencia y como parte de las ciencias actuales, impregnadas de un mercantilismo y un lucro sin límites, es dilucidar su sentido y sus fines según ya hemos mencionado, con un profundo significado ético: siempre hacerle el bien al ser humano y no dañarlo por ningún concepto. Así veo la lucha iniciada contra la medicalización, que la debe continuar un trabajo más efectivo para modificar la educación, de manera tal, que sea ésta y su calidad la que garantice que la inmensa mayoría de los estudiantes aprendan y se desarrollen, como se cree desde Vives y Comenio.

Las ciencias deben existir para mejorar y preservar la naturaleza y la psicología y la pedagogía deberían explicarnos cuáles son los orígenes y fuentes del desarrollo intelectual y afectivo, de la conciencia, de la autoconciencia y de toda la personalidad y cuál es en realidad el papel de lo biológico, lo social, lo cultural y lo propiamente psicológico que se va constituyendo y de qué manera estructural y funcionalmente, lo psicológico, participa en su propia constitución ulterior; para mejorar la forma de lograr en cada ser humano, en cada persona, la formación necesaria a través de la educación.

Deberíamos acabar de dilucidar cómo deben ser las relaciones sociales o interpersonales sanas que conducen a un desarrollo y a una formación humana plena, integral y no alienada; que engendren actividades y tipos de comunicaciones verdaderamente productivas y formadoras de un ser humano bien desarrollado, consciente, crítico, pleno e integral. Mostrar que se puede educar y producir mejores aprendizajes y desarrollos e incluso compensar los efectos de los déficits biológicos o los que se producen por las condiciones sociales y de una educación desfavorable. Creo que hay que estimular aun más estos temas de investigación que resultan esenciales para la búsqueda de soluciones a los problemas que estamos exponiendo.

Hasta ahora los diferentes paradigmas o teorías introducidos en la labor educativa y en la enseñanza, en los diferentes sistemas educacionales del mundo no han resuelto la existencia de escolares que no aprenden y con ello, la producción del fracaso y la fuga escolar.

Existe de hecho, y es algo que nos debe avergonzar, un desarrollo insuficiente en la población escolar de la función simbólica, del signo y el significado, que son necesarios para garantizar el mejor y mayor desarrollo del pensamiento y la inteligencia humana; no obstante, que se insista que lo humano está en el discurso y en el dominio de la palabra, es decir del lenguaje, el símbolo, el signo y el significado. ¿Qué consecuencias éticas y políticas tienen este divorcio entre lo que se promulga y lo que se hace en la educación y formación de las grandes poblaciones, particularmente las más desfavorecidas?

Ya sabemos que lo específicamente humano exige que las personas dominen en un grado necesario la función simbólica, el signo y los significados, como condición esencial para que se forme y desarrolle la mediación entre el lenguaje y el pensamiento, que transforma en lingüístico el pensamiento y en intelectual e interior al lenguaje, elevando el desarrollo intelectual y afectivo a los niveles más altos, convirtiendo a la persona en un ser social emancipado, crítico, independiente, autónomo, comprometido y productor de cultura. Todo el trabajo y la obra de Paulo Freire, es también un genuino referente para esto, al igual que lo que se postula en lo histórico cultural y en lo mejor de la cultura y la educación en Brasil, en América Latina y en el mundo, que estamos obligados a develar, estudiar y debatir a fondo, para mejorar la educación PARA TODOS, en función del llamado ético y político, que hoy nos hace en este Congreso ABRAPEE (Luz \& Caballero, 2001; Martí, 1975, 1983; Vygotski, 1991, 1993, 1995, 1996, 1999, 2004; Freire, 1971).

Las psicologías y las pedagogías tradicionales no han resuelto el triste problema de una educación de calidad para todos, porque a pesar de las fuertes criticas que han hecho sobre los sistemas educativos, las teorías y propuestas que han realizado, no asumen que son la educación y la enseñanza, las que contribuyen a desarrollar y emplear convenientemente las amplias posibilidades de aprendizaje y desarrollo de los seres humanos y el papel activo que ellos pueden llegar a tener y dejan, a las posibilidades intrínsecas del sujeto, la solución de los problemas, a partir esencialmente de los mecanismos internos.

Al no considerar las condiciones sociales y culturales, como parte estructural y constituyentes del desarrollo humano, no pueden proponer un cambio en las causas esenciales y entonces solo insisten en soluciones generales, a partir de conceptos abstractos, como las enormes potencialidades humanas, el papel activo del sujeto, el desarrollo espontaneo de las estructuras cognitivas, la continuidad del desarrollo cognitivo a partir de las estructuras biológicas, que le atañen solo al sujeto o esencialmente a los mecanismos internos del desarrollo psicológico; dejando de esta manera, a un lado las posibilidades reales de la vida o el drama humano en el que este vive y se desarrolla y que seguirá siendo limitado, castrado por la organización social, las formas de producción y la corrupción de las relaciones sociales. ¿Es esto ético y políticamente aceptable?

Por todo esto, los modelos tradicionales no pueden asumir, a plenitud el papel de una educación de calidad en el desarrollo psicológico humano, como lo comprende lo histórico cultural, ni destacar entonces, la necesidad e importancia, de una educación temprana o infantil que permita que los escolares lleguen al primer grado con un desarrollo básico o real que le facilite a él y al maestro, trabajar con mayor calidad para lograr mejores aprendizajes y desarrollos posteriores. Es en este momento de la existencia humana, donde se forman y desarrollan las bases de un desarrollo futuro 
de mayor calidad. No obstante, por otra parte se insiste en que los niños de menos de seis años deben aprender a leer, a escribir y a calcular, violentando así su momento del juego infantil, el dibujo y el conocimiento de los objetos, el perfeccionamiento del lenguaje como forma de comunicación, la formación y desarrollo de una atención y una concentración mas genuina y estable y la formación de un pensamiento en imágenes o representativo, base del formal o lingüístico, que se desarrollará después en los estudios de la educación primaria y media.

Los países que han mejorado los índices de aprendizaje en los escolares, han trabajado en la organización de una educación inicial, no solo para cuidar y proteger al niño, sino junto con esto, educar y promover el desarrollo, sin violentarlos, siguiendo el curso de las leyes que lo rigen.

Todo esto nos debe alertar sobre lo que debemos trabajar para lograr una mejor educación en la escuela y los centros educacionales, alcanzando una labor colaborativa y compartida entre la familia, la escuela y los diferentes segmentos de la sociedad, incluyendo los medios de comunicación.

Es por todo esto que a mi juicio, hasta el momento, el sistema de conocimiento más acabado, para sustentar lo que habría que hacer en la educación para todos y de calidad, es lo histórico cultural, porque parte de la idea de que el niño o la niña que nace, se constituirá en un ser humano independiente, autónomo y conscientemente activo y creador, cuando la educación sea promotora del desarrollo, lo arrastre a los límites posibles e incalculable, por medio de la apropiación de los contenidos y los medios culturales, inmersos en las relaciones sociales, la actividad y la comunicación en la familia, la escuela y la sociedad.

Para el enfoque histórico cultural, el sujeto requiere de la ayuda que necesite y solicite para aprender, formarse y desarrollarse, por eso es necesaria la educación. No es la ayuda que el educador o el portador de la cultura considere que necesita el estudiante, sino la ayuda que se le brinde a partir de lo que el propio sujeto necesite, reclame o demande, ante un nuevo problema o tarea. Este es el secreto, no es eliminar la ayuda... no es creer de manera absoluta en la solitaria producción educativa y cognitiva del escolar, sino organizar el ambiente social y cultural que promueva la colaboración cuando sea necesaria y de acuerdo con el principio de no violentar la posible autonomía e independencia del escolar (Vygotski, 1988, 2001, 1993, 1996; Arias, 2005, 2006, 2012; Fariñas, 2007; Calejon, 2012).

He centrado mis palabras en argumentos, explicaciones y proposiciones concretas que creo pueden contribuir a la lucha en post del ser humano y por la calidad de la Educación en este inmenso e importante pueblo y país que tiene un lugar y un papel significativo en las políticas regional y mundial. En defender que la educación comienza desde las edades mas tempranas y es permanente, garantizando constantemente nuevos y mas complejos aprendizajes que produzcan o arrastren a nuevos y más integrales o complejos desarrollos y así hasta lo infinito de las posibilidades de la constitución plena e integral de la personalidad humana.
Todo esto debe realizarse a través de estudios e investigaciones que permitan adecuar a las condiciones de Brasil, los logros que otros han obtenidos. Reunir todas y cada una de las experiencias positivas en este sentido, así como las dificultades que su aplicación conllevaron para producir modelos y formas de introducción a las condiciones específicas de Brasil. No es el momento de desesperarse o de copiar experiencias de otros países. Es el momento de producir, con seriedad, rigor y compromiso, lo que la ética y la buena política exigen.

Siempre he dicho que Brasil cuenta del nordeste hasta el sur y desde el extremo oeste hasta el Atlántico, con los especialistas y pensadores para ello, pienso que solo hay que producir proyectos y políticas que respondan a la necesidades concretas, de forma sistémica e integradoras que pudieran ser promovidas, entre otros, por ABRAPEE y que probándolas científicamente, sean propuestas para su aprobación e introducción en las prácticas educativas. Quizás todo esto sirva para lograr mas tarde los cambios definitivos que se necesitan en la sociedad y que sin dudas están ocurriendo según la marcha de la historia y de los procesos sociales en Brasil, en el continente y en el mundo. Nada debe frenar la búsqueda de soluciones a las necesidades, todo es un movimiento de transformación, de cambio y de desarrollo, la educación lo exige, el pueblo y nuestra ética personal también, nada mejor que ABRAPEE, se lo haya planteado.

Con su permiso...

Yo quisiera terminar estas palabras, con una idea intercultural más... citando a José Martí, un visionario latinoamericano de origen cubano y un maestro ejemplar, un latino americano convencido y luchador por la independencia de Cuba del yugo español...Que incluso creía que nuestros países y pueblos podrían contribuir, de manera excepcional, al equilibrio del Mundo que aun está por lograr...

Martí amaba nuestras leyendas indígenas y entre ellas, una de sus favoritas fue la del Padre Amalivaca y nos dice: como cuentan los indígenas del Amazona que para crear a los hombres y a las mujeres, el Padre Amalivaca regó por toda la tierra las semillas de la palma moriche...1

Martí parafraseando esta imagen mítica, en uno de sus excelentes y prometedores trabajos sobre la Educación del pueblo y el desarrollo del ser humano, titulado Maestros ambulantes lo concluyó diciendo: ¡Urge abrir escuelas normales de maestros prácticos, para regarlos luego por valles, montes y rincones...!

1 En la mitología indígena, Amalivaca fue el creador de la humanidad, del río Orinoco y del viento. En principio hizo a los hombres inmortales pero en castigo a su faltas, los volvió mortales. Se dice que hace muchos años atrás hubo una gran inundación. Amalivaca salió entonces en una canoa a recorrer el mundo y junto con su hermano Vochi fueron reparando los daños del diluvio, después del cual solo había quedado una pareja de humanos vivos. Ellos se fueron a una gran montaña llevando semillas de palma moriche y desde allí las dispersaron lanzándolas hacia el mundo. De estas semillas nacieron los hombres y las mujeres que pueblan el planeta. http://mitos-leyendas-urbanas.blogspot.com.br/2010/07/ amalivaca-y-la-creacion-del-mundo.html 
Por ello, a mi me gustaría terminar parafraseando estas dos ideas: estudiemos, investiguemos y conozcamos cómo mejorar nuestra educación y reguemos sus productos por todo Brasil, la América Latina y el Caribe, demostrándole al Mundo, que todos los niños y niñas cuando se les educan y se les enseñan bien, aprenden y se desarrollan, disminuyéndose sensiblemente el fracaso escolar que hoy existe debido a las sociedades injustas e inhumanas en las que aun vivimos...

Muchas Gracias.

\section{Referencias}

Moysés, M.A.A. \& Collares, C. L. (2010) Dislexia e TDAH: uma análise a partir da ciência médica. En Conselho Regional de Psicologia (Org.) Medicalização de Crianças e Adolescentes. Conflitos silenciados pela redução de questões sociais a doenças de indivíduos. São Paulo: Casa do Psicólogo.

Arias, G. (2001). Evaluación y Diagnóstico en la Educación y el Desarrollo. Desde el Enfoque Histórico Cultural. São Paulo: Editor Laura Marisa Carnielo Calejon.

Arias, G. (2005). Desarrollo histórico de los escolares con necesidades educativas especiales. Apuntes y consideraciones. En Psicología Especial Tomo I Colectivo de autores. Ciudad de la Habana, Cuba: Editorial Félix Varela.

Arias, G. (2005a). La Persona en el Enfoque Histórico Cultural. São Paulo: Editora Linear B.

Arias, G. (2006). Inteligência e Educação. São Paulo: Terceira Margem Editora.

Arias, G. (2012). Una concepción integradora sobre el desarrollo del ser humano y su importância en la educación. En M. A. Lima e Dias; K. Fukumitsu; A. Melo. Temas contemporaneos em psicologia do desenvolvimento. São Paulo: VETOR.

Bacon, F. (1961). Novum Organum. Buenos Aires: Editorial Losada S.A.

Calejon, L. M. C. (2012). Desenvolvimento humano : uma reflexão a partir do enfoque histórico-cultural. En Lima e Dias Marián Avila; Fukumitsu Karina ; Melo Aurélio. Temas contemporaneos em psicologia do desenvolvimento. São Paulo: VETOR.

Calejon, L. M. C. (2011). Desempenho escolar e Vulnerabilidade Social. Revista Exitus UFOPA. (1), 1.

Chang, F. E. \& Greenough, W. (1985). Synaptic estructural correlates of information storage in mammalian nervous systems. En C. W. Cotman. Synaptic plasticity. New York: The Guilford Press, pp. 335 -372 .
Comenio, A.J. (1983). Didáctica Magna. Ciudad de la Habana, Cuba: Editorial Pueblo y Educación.

Elkonin, D. B. (1984). Psicología del juego. Ciudad de la Habana, Cuba: Editorial Pueblo y Educación.

Fariñas León G. (2007). Psicología, Educación y Sociedad. Ciudad de la Habana, Cuba: Editorial Félix Varela.

Freire, P. (1971). La educación como práctica de la libertad. España: Siglo XXI.

Galperin, P. Y. (1988). El problema sobre los instintos en el hombre, en: Selección de psicología de las edades. La Habana: Facultad de psicología, Universidad de la Habana, tomo III, pp. 5 - 24.

Golder, M. (1986). Reportajes contemporáneos a la PSICOLOGIA SOVIETICA. Buenos Aires: Editorial Cartago.

Gould, J. S. (2007). The RICHNESS of LIFE. The essential STEPHEN JAY GOULD. Edited by Esteven Rose. New York: W.W.Norton \& Company.

Gould, J. S. (1997). La falsa medida del hombre. Barcelona, España: Editorial Drakontos.

Greenough, T. W. (1975). Modificación experimental del cerebro en desarrollo. American Scientist, 63, pp. 37-46.

Griffiths, A. J. F., Gelbait, W. M., Miller, T. H. \& Lewontin, L. C. (1999). Modern Genetic Analysis. W.H. Freeman and Company.

Guarido, R. (2010). A biologização da vida e algumas implicações do discurso médico sobre a educação. En Conselho Regional de Psicologia (Org.) Medicalização de Crianças e Adolescentes. Conflitos silenciados pela redução de questões sociais a doenças de indivíduos. São Paulo: Casa do Psicólogo.

Hinkelammert, F. J. (2006). El sujeto y la ley. El retorno del sujeto reprimido. La Habana, Cuba: Editorial Caminos.

Kamin, L. J. (1983). Ciencia y política del cociente intelectual. Madrid, España: Siglo XXI de España Editores, S. A.

Lenin, V. I. (1961). Obras Escogidas en tres tomos. Moscú: Editorial Progreso.

Lewontin, R.C, Rose, S. \& Kamin, L. J. (1987). No está en los genes. Barcelona: Ed. Crítica.

Luz y Caballero, J. (2001). OBRAS. Escritos educativos, Volumen II. La Habana, Cuba: Editorial IMAGEN CONTEMPORÁNEA.

Manacorda, M. A. (2010). História da Educação. Da antiguidade aos nossos dias. São Paulo: Editora Cortez. 
Martí, J. (1975). José Martí. Obras Completas. La Habana, Cuba: Editorial de Ciencias Sociales.

Martí, J. (1983). Otras crónicas de Nueva York. La Habana, Cuba: Editorial de Ciencias Sociales.

Marx, C. \& Engels, F. (1986). Obras Escogidas. Tomo I (en tres tomos). Moscú: Editorial Progreso.

Mustard, F. J. (2005). Early Child Development and Experiencebased Brain Development. The Scientific Underpinnings of the Importance of Early Child Development in a Globalized World (This paper was prepared for the World Bank International Symposium on Early Child Development-A Priority for Sustained Economic Growth \& Equity, September 27-29. Excerpts from this paper are under preparation for publication by The World Bank in the proceedings of the meeting. 2006).

Nature, International Human Genome Sequencing Consortium, Initial sequencing and analysis of the Human Genome. (2001). Nature (409) 6822 pp. 860-921.

Netto, P.J. (2011). Introdução ao estudo do método de Marx. São Paulo: Editora Expressão Popular.

Patto, M.H. (1995). A produção do fracasso escolar: histórias de sumissão e rebeldia. São Paulo: T .A. Queiroz.

Ponce, A. (1975). OBRAS. La Habana, Cuba: Editorial Casa de las Américas.

Portes, P. R. (1999). Social and Psychological factors in the academic achievement of children of immigrants: Cultural historical puzzle. American Educational Research Journal, 36(3), pp. 489-507.

Portes, P. R. (2005). Dismantling educational inequality: A Cultural historical approach to closing the achievement gap. New York, NY: Peter Lang Publishing.

Portes, P. R. (2006). A Portrait of immigrant American. California: University Press Berkeley.

Souza, M. P. R. (2010). Retornando a patologia para justificar a não aprendizagem escolar: a medicalização e o diagnostico de transtornos de aprendizagem em tempos de neoliberalismo. En Conselho Regional de Psicologia (Org.) Medicalização de Crianças e Adolescentes. Conflitos silenciados pela redução de questões sociais a doenças de indivíduos. São Paulo: Casa do Psicólogo.

Souza, M. P. R. \& Cunha, B. B. B. (2010). Projeto de lei e politicas públicas: o que a psicologia tem a propor para a educação? En Conselho Regional de Psicologia (Org.) Medicalização de Crianças e Adolescentes. Conflitos silenciados pela redução de questões sociais a doenças de indivíduos. São Paulo: Casa do Psicólogo.
Tanamachi, E. R. (2007). A psicologia no contexto do materialismo histórico dialético: elementos para compreender a psicologia histórico-cultural. Em Psicologia Histórico Cultural Contribuções para o encontro entre a subjetividade e a educação. M. E. M. M. \& M. G. D. F. (Orgs.). São Paulo: Casa do Psicólogo.

Venter, J.C. et al. (2001). The Sequence of the Human Genome. Science (291) 5507.

Vygotski, L. S. \& Luria, A. R. (2007). El instrumento y el signo en el desarrollo del niño. Editor Fundación Infancia y Aprendizaje.

Vygotski, L. S. (1987). Historia del desarrollo de las funciones psíquicas superiores. Ciudad de La Habana, Cuba: Editorial Científico Técnica.

Vygotski, L. S. (1988). Interacción entre enseñanza y desarrollo. En el libro Selección de Lecturas de Psicología de las Edades I. Colectivo de Autores, Facultad de Psicología Universidad de La Habana, Editorial del Ministerio de Educación superior.

Vygotski, L. S. (1989). Obras Completas, Tomo V. La Habana: Editorial Pueblo y Educación.

Vygotski, L. S. (1991).Obras Escogidas, Tomo I. Madrid, España: Editorial Aprendizaje/Visor.

Vygotski, L. S. (1993). Obras Escogidas Tomo II. Madrid, España: Editorial Aprendizaje/Visor.

Vygotski, L. S. (1995). Obras Escogidas Tomo III. Madrid, España: Editorial Aprendizaje/Visor.

Vygotski, L. S. (1996). Obras Escogidas, Tomo IV.: Editorial Aprendizaje/Visor.

Vygotski, L. S. (1999). Ciudad de la Habana, Cuba: Imaginación y creación en la edad infantil. Editorial Pueblo y Educación $\left(2^{2}\right.$ edición).

Vygotski, L. S. (2001). Psicología Pedagógica. Un curso breve. Buenos Aires, Argentina: Aique Grupo Editor S.A.

Vygotski, L. S. (2004). Teoría de las Emociones. Estudio históricopsicológico. Madrid, España: Ediciones Akal, S.A.

Vives, J. L. (1997). Las disciplinas. Ayuntamiento de Valencia, Valencia, España. Artes Gráficas Soler. 


\section{Sobre o Autor}

Guillermo Arias Beatón (gariasbeaton@gmail.com)

Presidente Cátedra L.S. Vygotski

Facultad de Psicología, Universidad de La Habana 